\title{
Social Media News Use and Political Cynicism: Differential Pathways Through "News Finds Me" Perception
}

\section{Hyunjin Song, Homero Gil de Zúñiga \& Hajo G. Boomgaarden}

To cite this article: Hyunjin Song, Homero Gil de Zúñiga \& Hajo G. Boomgaarden (2019): Social Media News Use and Political Cynicism: Differential Pathways Through "News Finds Me" Perception, Mass Communication and Society, DOI: 10.1080/15205436.2019.1651867

To link to this article: https://doi.org/10.1080/15205436.2019.1651867

\section{(c) 2019 The Author(s). Published with license by Taylor \& Francis Group, LLC}

\section{t+}

View supplementary material $\widetilde{ }$

Accepted author version posted online: 02
Aug 2019.
Published online: 16 Aug 2019.

Џ Article views: 714

Q View related articles ¿

View Crossmark data $\asymp$ 


\title{
Social Media News Use and Political Cynicism: Differential Pathways Through "News Finds Me" Perception
}

\author{
Hyunjin Song $\mathbb{B}^{\circ}$, Homero Gil de Zúñiga ${ }^{\circ}$, and \\ Hajo G. Boomgaarden \\ Department of Communication \\ University of Vienna
}

As citizens inadvertently "encounter" news and political information through digital media and social networking sites, they might perceive themselves to be well informed about politics without actively seeking political information, which has been labeled as the "News Finds Me" (NFM) perception. We attempt to explicate and further advance the conceptualization and corresponding measurement of "News Finds Me" perception.

Hyunjin Song (Ph.D, The Ohio State University, 2015) is an assistant professor in the Department of Communication at the University of Vienna. His research interests include the influence of media use and interpersonal discussion on political engagement and computational methods.

Homero Gil de Zúñiga (Ph.D, University of Wisconsin, Madison, 2008) is Medienwandel Professor in the Department of Communication at the University of Vienna. His research interests include the influence of new technologies and digital media over people's daily lives, as well as the effect of such use on the overall democratic process.

Hajo G. Boomgaarden (Ph.D, University of Amsterdam, 2007) is Professor for Empirical Social Science Methods in the Department of Communication at the University of Vienna. His research interests include the coverage and effects of political information on citizens' cognitions, attitudes and behaviors in various domains of media and politics, and developments in automated content analysis techniques.

Correspondence should be addressed to Hyunjin Song, Department of Communication, University of Vienna, Rathausstraße 19/1/9, Vienna, 1010 Austria. E-mail: hyunjin.song@univie.ac.at

Color versions of one or more of the figures in the article can be found online at www. tandfonline.com/HMCS.

This is an Open Access article distributed under the terms of the Creative Commons AttributionNonCommercial-NoDerivatives License (http://creativecommons.org/licenses/by-nc-nd/4.0/), which permits non-commercial re-use, distribution, and reproduction in any medium, provided the original work is properly cited, and is not altered, transformed, or built upon in any way. 
Using a nationally representative survey conducted in Austria, our analysis shows that social media news use may contribute to cynicism towards politics, and that such a relationship is critically mediated through NFM perceptions, but to a differential degree depending on specific sub-dimensions of NFM perceptions.

With the advance of digital media and social networking sites (SNS) such as Facebook and Twitter, citizens across the globe are experiencing dramatic changes in the way they receive political information. Increasingly, those platforms act as primary outlets through which citizens encounter news stories. This trend is evident across the globe, such that approximately more than one third - sometimes more than half - of the citizens of 27 countries around the world use social media for discovering and consuming news content (Newman, Fletcher, Kalogeropoulos, Levy, \& Nielsen, 2018).

Many social media users also use social media to disseminate and discuss news with others (e.g., Lee \& Song, 2017). Inevitably, users within these social networks will be exposed to news contents without any explicit or intentional effort of their own (Fletcher \& Nielsen, 2018; Kim, Chen, \& de Zúñiga, 2013). While maintaining connections with family and friends remains the primary reason for using social media, the increase in news circulation via social media or messaging applications (e.g., Toff \& Nielsen, 2018) may suggest that the chance of people being "inadvertently" exposed to and consuming news content becomes all the greater (e.g., Valeriani \& Vaccari, 2016; Weeks, Lane, Kim, Lee, \& Kwak, 2017).

As citizens increasingly encounter news and relevant political information without any explicit effort through social media platforms, they also might perceive themselves to be well informed about politics without actively seeking for political information, which has been labeled as the "News Finds Me" (NFM) perception (Gil de Zúñiga, Weeks, \& Ardèvol-Abreu, 2017; also see Fletcher \& Nielsen, 2018). Recent studies grappling with this concept suggest that high NFM perceptions uniquely - and most importantly, negatively - relate to citizens' acquisition of political knowledge, political interest, and voting (Gil de Zúñiga \& Diehl, 2019; Valenzuela, Bachmann, \& Gil de Zúñiga, 2018, May) - despite individuals with high NFM perceptions frequently consuming news from social media.

Against this backdrop, the goal of this contribution is twofold. First, we attempt to explicate and further advance the conceptualization and the corresponding measurement of the "News Finds Me" perception. A more thorough conceptual and empirical validation of the NFM scale is necessary, given the complex nature of the construct. To this end, we propose that the NFM perception should be considered as a tripartite, higher-order construct consisting of three subdimensions: (a) "being informed" (epistemic), (b) "not seeking" (motivational), and (c) "reliance on peers" (instrumental dimension). We seek to (theoretically) investigate and (empirically) confirm this internal factor structure of the NFM measurement items by exploring its possible correlates and 
predictors, focusing on social media news use and one's perceptions of their peers' political expertise.

Second, we explore indirect consequences of social media news use through NFM perception on individuals' political system-level perception concerning political cynicism, taking the dimensionality of NFM into account. Political cynicism is one of the key elements in assessing people's overall confidence in government and democratic systems, which subsequently relate to important political outcomes such as participation and voting. A handful of previous studies focused on the impact of media use on political cynicism, but so far, they were largely confined to more active forms of media consumption on traditional media (e.g., Hutchens, Hmielowski, Pinkleton, \& Beam, 2016; Pinkleton \& Austin, 2002). With the notion of NFM perception - in particular its motivational dimension - suggesting a relatively passive nature of news consumption, it is largely unknown whether, and how, such a passive mode of news consumption is related to citizen's political system-level perceptions.

Given the increasing prominence of social networking sites for online news consumption and increasing political disengagement across Europe and beyond, our investigation sheds important insights on how the changing nature of online news consumption affects citizen's attitudes and satisfaction towards democratic engagement in a more nuanced way. While prior contributions on this topic have examined the (mostly negative) effect of NFM perception on knowledge and participation primarily within the U.S. context, we extend this line of work by examining the possible correlates and its effect of NFM perception within a different political context (Austria), which has a much more traditional news environment than the U.S. Using a nationally representative survey conducted in Austria, our analysis shows that social media news use may contribute to lower levels of cynicism, and that such a relationship critically depends upon NFM perceptions, but to a different degree depending on specific sub-dimensions of NFM perceptions.

\section{THE DIMENSIONALITY AND THE ANTECEDENTS OF NEWS-FINDS-ME PERCEPTION}

The News Finds Me (NFM) perception is defined as "[emphasis added] the extent to which individuals believe they can indirectly stay informed about public affairs - despite not actively following the news - through general Internet use, information received from peers, and connections within online social networks" (Gil de Zúñiga et al., 2017, p. 107). Contrary to avoidance of (hard) news altogether (Ksiazek, Malthouse, \& Webster, 2010) or preferences toward entertainment contents over hard news (Prior, 2005), the NFM perception purportedly captures an individual's idiosyncratic "passive" motivation of 
consuming news contents, or lack thereof. At first glance, such perception simply appears to stem from an individual's epistemic belief that they themselves are being "well informed" about current events and political affairs (Gil de Zúñiga et al., 2017). Yet the close reading of the initial conceptualization of NFM perception presupposes a very specific set of conditions, compared to the traditional notion of citizen competence coupled with active information seeking behaviors (e.g., Valentino, Hutchings, Banks, \& Davis, 2008).

Besides the epistemic belief that people rating high on NFM are being "well informed", another core element of NFM perception is the notion that one needs not actively follow the news with explicit efforts. This motivational basis of NFM perception presumably plays an important role in the current conceptualization of NFM perception, highlighting the passive and "incidental" nature of indirect news exposure within the contemporary high-choice information environment. In other words, the "incidental" nature of citizens' competence expressed in NFM perception is squarely captured by this motivational subdimension of NFM perception. In a highly saturated media environment, acquiring politically relevant information may not need much active effort due to abundant information availability (Elenbaas, Boomgaarden, Schuck, \& de Vreese, 2013; Prior, 2005). In such a setting, passive learning can occur independently of one's political motivation and attention to contents (Bode, 2016; Shehata, 2014). Therefore, individuals may believe they can sufficiently stay informed about public affairs (epistemic "being informed" dimension) despite not purposefully following news (motivational "not seeking" dimension). Based on this logic, we predict that individuals' frequent use of social media for news will be positively related to two sub-dimensions of NFM perception:

H1: Social media use for news will be positively related to the "being informed" dimension (H1a) and the "not seeking" dimension (H1b) of NFM perception.

Another important feature of the NFM perception is the notion that people can rely or delegate the process of acquiring necessary political information to their social network peers ("reliance on peers" dimension), which captures the instrumental aspect of NFM perception. Similar to the aforementioned availability-based logic, one can easily obtain politically relevant information within (online) social networks due to others sharing such contents. While individuals do not exclusively use social media as a tool for satisfying their information-seeking and surveillance needs (Lee \& Ma, 2012), inevitably they can satisfy such needs if other users within these social networks share news contents that are relevant for them (Fletcher \& Nielsen, 2018; Kim et al., 2013; Toff \& Nielsen, 2018). Indeed, studies suggest that citizens are more likely to engage with those whom they perceive to be able to provide a shortcut to political 
information (Huckfeldt, 2001; Sokhey \& McClurg, 2012). This "division of labor" in political information acquisition has long been recognized as a potential source of political learning (e.g., Berelson, Lazarsfeld, \& McPhee, 1954; Downs, 1957). Based on this logic, we expect that (a) those who perceive their social contacts ("alters") to have higher political expertise, and (b) those who heavily use social media for political purposes may rely more on such delegation in acquiring political information. Therefore:

$\mathrm{H} 2$ : Alter political expertise perceptions (H2a) and social media news use (H2b) will be positively correlated with the "reliance on peers" dimension of NFM perception.

\section{DEMOCRATIC IMPLICATIONS OF NEWS-FINDS-ME PERCEPTION}

For decades, citizens have voiced a persistent feeling of skepticism toward and distrust in government (Kriesi et al., 2012). Individuals may perceive that politicians deal with important issues in a superficial manner, or take decisions based on strategic electoral positioning rather than based on the genuine interest of the electorates. This type of perception leads to what has been coined as political cynicism, or "a (perceived) gap between voters and their political representatives" (Schuck, Boomgaarden, \& de Vreese, 2013, p. 288), which (typically) accompanies skepticisms and distrust towards a political system. There is abundant literature documenting a large degree of political skepticism towards elected officials among the general public, ranging from distrust in government and political institutions (Cook \& Gronke, 2005) to overall disaffection with the liberal democratic principles at the expense of populist appeals (Fieschi \& Heywood, 2004).

While the role of traditional media such as newspapers and television in promoting political cynicism is now well documented (e.g., Cappella \& Jamieson, 1996; De Vreese \& Elenbaas, 2008), some prior evidence (quite conversely) suggests that increased access to websites of news media and news organizations may increase trust toward political systems (therefore may lower political cynicism: Bailard, 2014; Ceron, 2015). These studies generally argue that increased access to political information afforded by the Internet may offer better dissemination of information regarding the performances of governments and institutions to their citizens, therefore is likely to increase democratic satisfaction (such as increased trust and decreased cynicism) especially in wellfunctioning democratic countries (Bailard, 2014; Ceron, 2015). However, the question of to what extent news exposure on social media in particular may contribute to political cynicism is still insufficiently addressed. Research has shown that when the information is shared by their peers, people tend to trust given information more (Turcotte, York, Irving, Scholl, \& Pingree, 2015), and 
are more likely to engage with such contents even if such contents are counterattitudinal (Messing \& Westwood, 2014). In addition, research suggests that those who may not otherwise actively seek out news due to their low level of interest and motivations (Prior, 2005) indeed often are influenced by mere exposure to media contents independent of their level of interest and motivations (e.g., Cappella \& Jamieson, 1996; Shehata, 2014). Given increasing trends in incidental news exposure via social media (Toff \& Nielsen, 2018; Valeriani \& Vaccari, 2016), we argue that such inadvertent exposure without explicit effort may have important ramifications in understanding citizens' confidence towards politics.

An increasing number of studies suggests that cynicism can be understood as a function of specific - oftentimes, negative - contents such as negative advertising and strategic and "game-framed" news (e.g., Cappella \& Jamieson, 1996; De Vreese \& Elenbaas, 2008; Schuck et al., 2013; Shehata, 2014). News use therefore tends to increase political cynicism especially among those who are politically interested, to the extent that such attentive voters have more exposure to such negative coverage (Cappella \& Jamieson, 1996; De Vreese \& Elenbaas, 2008; Shehata, 2014). Yet past studies have also shown that political cynicism is negatively related to "active" media consumption and political involvement (e.g., Pinkleton \& Austin, 2002), suggesting a relatively passive form of media use may promote further political cynicism while active media use - and the perception of being sufficiently informed for that matter - may be negatively related to level of political cynicism. This is because peripheral processing (i.e., lack of active, systematic processing) of game-framed, strategic news frame automatically activates negative considerations towards politics.

Prior research indicates that more controversial, conflictual, and negative news stories are relatively more often shared online (e.g., Burggraaff \& Trilling, 2017; Trilling, Tolochko, \& Burscher, 2017), and relatedly, relatively passive and effortless processing of such stories may further activate negative considerations towards politics in general. For instance, Shehata's (2014) analysis shows that motivated news attention substantially diminishes negative effects of game-framed news coverage on political trust and engagement, while Ceron's (2015) analysis suggests that an increased news consumption via social media has a particularly negative consequence for citizens' trust towards political institutions compared to news consumption via online news media (such as websites of traditional news organizations). Since the two subdimensions of NFM perception - "not seeking" and "reliance on peers" - represent relatively passive, incidental consumption of (often negative and conflictual) news stories on social networking websites without active engagement, this is one of the main reasons why political cynicism and NFM should be positively associated. 
Since those who lack motivation to actively engage with news are likely to effortlessly process negative and sensational news stories being available to them via online social networks, we therefore may expect that "not seeking" and "reliance on peers" dimensions of NFM perception, which represent relatively passive and effortless motivations of consuming news contents, should further promote political cynicism. Yet on the other hand, to the extent that individuals perceive themselves to already be sufficiently informed about public affairs, such individuals would be less likely to show cynicism towards political systems - similar to those who are on top of the news, vigilant, always attentive and functioning as opinion and information "watchdogs." This implies the "being informed" dimension of NFM perception would be negatively related to political cynicism. Additionally, considering the fact that social media use would positively predict NFM perception, we expect NFM perceptions to mediate the influence of social media use on political cynicism. Therefore, we posit:

H3: While "reliance on peers" (H3a) and "not seeking" (H3b) dimensions will positively predict political cynicism, "being informed" (H3c) dimension will negatively predict political cynicism.

H4: Social media use will indirectly increase political cynicism through "reliance on peers" (H4a) and "not seeking" (H4b) dimension, whereas decrease political cynicism through stay informed" (H4c) dimension of NFM perception.

\section{METHODS}

\section{Sample}

The study relies on a nationally representative survey conducted in Austria, fielded from September 15th to October 31st, 2017. The survey was conducted and administered by Statistics Austria, an independent public institution responsible for providing national-level census and polling. The survey was commissioned by the Platform for Survey Research, Methods and Empirical Analysis (PUMA), financed by the Austrian Federal Ministry of Education, Science and Research. The protocol regarding research on human subjects were reviewed and approved by PUMA prior to the fieldwork.

Based on a central population register of the Austrian population, Statistics Austria used multistage stratified random sampling based on key demographics to draw a total of 1500 representative participants. Eligible participants were given a mail invitation, where were given a code for online access to the survey and identical paper-and-pencil questionnaire (either with the initial invitation code or as a follow-up reminder). Among them, a total of 641 respondents have 
participated in the survey (AAPOR RR1: 42.7\%). Our sample contained slightly more females (sample $=54 \%$ female; population $=51 \%$ female) and was slightly older (sample: mean $=45.65$, median $=47$; population: median range $=40$ to 44 years) than the general population, but largely representative in terms of education (both sample and population median $=$ Intermediate technical and vocational schools) and net household income (sample median $=2201$ to 2600 EUR, population: mean $=2158$ EUR). ${ }^{1}$

\section{Measurements}

News-Finds-Me Perception. The NFM perception was measured based on agreement (on a 10-point scale ranging from "strongly disagree" $=1$ to "strongly agree" $=10$ ) with a series of statements from Gil de Zúñiga et al. (2017). Given that the original construct generated in that study included four items - two items for reliance on peers, and one item for informed and not seeking, respectively, this study included two additional statements that closely capture those single-item sub-dimensions to improve the measurement (the informed dimension now includes "I do not worry about keeping up with news because I know news will find me," and the not seeking dimension includes "I do not have to actively seek news because when important public affairs break, they will get to me through social media"). Accordingly, all three sub-dimensions of the NFM construct have now two items each. Panel A in Table 1 reports item wordings and descriptive statistics. For subsequent regression analysis (including propensity score weighting), we constructed scales for each sub-dimension (Reliance on peers: $M=3.73$, $S D=2.30$, Spearman-Brown $\rho=.658$; Informed: $M=4.60, S D=2.43$, $\rho=.494$; Not seeking: $M=4.89, S D=2.39, \rho=.690){ }^{2}$

Social Media News Use. Following Gil de Zúñiga et al. (2017), social media use for news purpose was captured as an index of eight items measured on a 10 -point scale $(1=$ never to $10=$ all the time, $M=3.67, S D=1.91$, $\alpha=.76$ ). Five items asked about respondents' exposure to news through Facebook, YouTube, WhatsApp, Twitter, and Google ("how often you use

\footnotetext{
${ }^{1}$ All reported population characteristics are from 2015 labor market statistics, provided by the Federal Bureau of Statistics Austria.

${ }^{2}$ Some of the item wordings in NFM scale appears to address two subdimensions at the same time. To address this issue, we validate our main analysis by using extracted factor scores from EFA (instead of a scale mean of relevant items) as the score for sub-dimensions. This robustness check, which appears in Table A5 to A6 of the online appendix, suggests that our multidimensional conceptualization itself and corresponding results are reasonably robust, although our NFM perception question wordings are less than ideal.
} 
TABLE 1

Question Wordings and Model Fit Comparisons

\begin{tabular}{|c|c|c|c|}
\hline & Panel A. Question & Wording for NFM Perception and Its Sub-dimensions & $J=641)$ \\
\hline Items & Dimension & Item wordings & $\mathrm{M}(\mathrm{SD})$ \\
\hline 1 & Reliance on peers & $\begin{array}{l}\text { I rely on my friends to tell me what's important } \\
\text { when news happen }\end{array}$ & $4.57(2.95)$ \\
\hline 2 & Informed & $\begin{array}{l}\text { I can be well-informed even when I don't actively } \\
\text { follow the news }\end{array}$ & $5.28(2.73)$ \\
\hline 3 & Informed & $\begin{array}{l}\text { I do not worry about keeping up with news because } \\
\text { I know news will finds me }\end{array}$ & $4.55(2.75)$ \\
\hline 4 & Reliance on peers & $\begin{array}{l}\text { I rely on information from my friends based on } \\
\text { what they like or follow through social media }\end{array}$ & $2.92(2.38)$ \\
\hline 5 & Not seeking & $\begin{array}{l}\text { I do not have to actively seek news because when } \\
\text { important public affairs break, they will get to me } \\
\text { in social media }\end{array}$ & $4.04(3.08)$ \\
\hline 6 & Not seeking & $\begin{array}{l}\text { I'm up-to-date and informed about public affairs } \\
\text { news, even when I do not actively seek news } \\
\text { myself }\end{array}$ & $5.13(2.88)$ \\
\hline
\end{tabular}

Panel B. A Comparison of the Single Factor Model Vs. Three-factor Model of NFM

\begin{tabular}{lccccc}
\hline Models & Chisq (df) & CFI & TLI & RMSEA [90\% CIs] & SRMR \\
\hline Single factor & $106.20(8)^{* * *}$ & .872 & .759 & $.139^{* * *}[.116, .163]$ & .056 \\
Three-factor & $8.71(5)$ & .995 & .985 & $.029[0, .071]$ & .016
\end{tabular}

Note. Model fit comparison yields $\chi^{2}$-diff $=97.48, d f=3, p<.001$, showing hypothesized threefactor model fits significantly better to the data than the single-factor model. All model $N=638$.

following social media [via computer, tablet, mobile, or any device] for getting news online"). In addition, three more general items ("I use social media to stay informed about current events and public affairs," "I use social media to get news about current events from mainstream media," and "I use social media to get news from online news sites," all of which were also based on the same 10point scale) captured their attention and motivations, therefore collectively tapping general online news use. ${ }^{3}$

Political Cynicism. Political cynicism is captured by six items (on a 5-point scale from "strongly disagree" = 1 to "strongly agree" $=5$ ) asking respondents' attitudes towards elected politicians in general $(M=2.28, S D=.64$,

\footnotetext{
${ }^{3}$ The combined measure of exposure and attention is regarded as one of the best approaches of measuring a general concept of media "use," which reflects the correspondence between exposure to a source and devotion of cognitive effort to that source at the same time (Eveland, Hutchens, \& Shen, 2009).
} 
$\alpha=.74$ ), adopted from Boukes and Boomgaarden (2015). Items include: "Politicians often argue too much with each other," "MPs and ministers do not care much about what people like me think," "Politicians are particularly interested in their own interest," "Politicians spend too much time discussing, and too little governing," "Most public officials are truly interested in what the people think" (recoded), and "Most politicians are competent people who know what they are doing" (recoded).

Alter Political Expertise Perceptions. Respondents were also asked about the perception of each of their social network ties' political expertise levels (based on a 5-point scale from "not at all knowledgeable" = 1 to "very much knowledgeable" = 5) for strong and weak ties. A summary index of alter political expertise perception was derived by averaging the two $(M=3.14, S D=.64$, Spearman-Brown $\rho=.630){ }^{4}$

Control Variables. In order to account for potential confounders, a host of control variables were included in the analysis, including respondents' gender ( $54 \%$ female, coded as 1, otherwise zero), age (in 10-year increments, $M=4.55$, $S D=1.65$ ), and education attainment (Median $=7$ ["Teaching or vocational school"], range $=1$ "from no school attended" to 14 "Doctor/PhD"). We control for talk frequency $(M=2.72, S D=.87$, Spearman-Brown $\rho=.684)$, which was assessed by asking how often they talk about politics with their strong (i.e., family and close friends) and weak ties (i.e., coworkers, and acquaintances) whether online or offline (based on a 5-point scale from "never" = 1 to "very often" $=5)$. In addition, we also include political interest $(M=2.63, S D=.87$, from $1=$ "not at all interested" to $4=$ "very interested") and internal efficacy $(M=3.61, S D=1.21$, from $1=$ "strongly disagree" to $5=$ "strongly agree"), measured by one item with the following statement: "People like me don't have any say in what public officials do" (recoded).

\section{Analysis Strategy}

First, we employed a series of confirmatory factor analysis (CFA) to empirically test the three-dimensional structure of the NFM perception. We do so by comparing a baseline single-factor model with the proposed three-factor model using $\chi^{2}$ test statistics. We further validate the proposed three-factor model of the NFM perception by examining NFM perception's convergent and discriminant validity with other logically similar constructs. Convergent

\footnotetext{
${ }^{4}$ The zero-order correlation between strong vs. weak talk frequency was .52, and the zero-order correlation between strong vs. weak alter expertise perception was 46 .
} 
validity was examined via its correlation structure between NFM subdimensions and theoretically related variables, whereas a discriminant validity is examined by comparing models with and without equality constraints being imposed between each dimension of the NFM and other logically similar constructs (Hayes, Glynn, \& Shanahan, 2005).

Second, we conducted a series of OLS regression analysis, coupled with a propensity score weighting analysis (Imai \& Ratkovic, 2014) and Monte-Carlo inferences for mediation (Hayes, 2017; Preacher \& Selig, 2012). In order to address the limitations of cross-sectional data, we employed the Covariate Balancing Generalized Propensity Score (CBGPS) methodology proposed by Fong, Hazlett, and Imai (2018; also see Imai \& Ratkovic, 2014). The CBGPS weighting attempts to reduce self-selection bias by reducing correlations between a continuous "treatment" variable and a set of relevant pre-treatment covariates. This can be seen as a substitute for randomization, where the goal of such a propensity score procedure is to produce an unbiased comparison between cases that are indistinguishable in terms of their relevant background characteristics except a "treatment" variable of interest. When applied to observational data, post-adjusted data (using estimated propensity score weights) would have similar balancing properties that can be found in a randomized experiment. We estimate two CBGPS models predicting two "treatment" variables (i.e., social media news use and NFM perception, respectively) and subsequently utilize CBGPS weights in the outcome analysis (see below for more detail). Given a host of other demographic and political correlates of the NFM perception, and for the ease of application of propensity score weighting, we opted to rely on OLS regression-based procedures rather than structural equation models. All analyses were conducted using $R$ statistical software, with Lavaan (Rosseel, 2012) and CBPS package (Fong, Ratkovic, \& Imai, 2018).

\section{RESULTS}

\section{Confirmatory Factor Analysis of News Finds Me Sub-dimensions}

First, we compare the model fit between the single-factor CFA model (assuming all observed variables belong to the single "NFM" latent construct) and that of the multi-factor CFA model. ${ }^{5}$ In the single-factor CFA model, covariances among sub-dimensions are fixed to 1 (therefore all sub-dimensions are treated as the

\footnotetext{
${ }^{5}$ We allow residuals between the items mentioning social media (item 4 and item 5 in NFM scales) to be correlated, in order to capture any residual covariation due to question wordings. Also, we scale the variances of the latent construct to be 1 (with their residual error variances set to zero), so any covariance estimates between latent constructs are to be interpreted as correlations among those latent factors.
} 
single latent factor), whereas in the multi-factor CFA model, such constraints are released. Although both the single-factor model and the three-factor model indeed showed acceptable model fit (as can be seen in Panel B of Table 1), the difference in the model fit statistics between the single-factor and the hypothesized threefactor model was statistically significant, $\chi^{2}$-diff $=97.48, d f=3, p<.001$, confirming that the three sub-dimensions of NFM perceptions are unique.

As an initial examination of the validity, we further assessed within- and across-correlations of each NFM scale item with the three sub-dimensions. As can be seen in Table A1 of the online appendix, each observed variable that belongs to each of the sub-dimensions most strongly correlated with that specified sub-dimension but not with others, further supporting the appropriateness of our three-dimensional structure of NFM.

\section{Convergent and Discriminant Validity of News Finds Me Sub-dimensions}

Having established the appropriateness of the three-factor structure of NFM perception, we now assess their additional evidence of convergent and divergent validity. As previously noted, convergent and discriminant validity was examined via (a) the correlations between latent variables of NFM sub-dimensions with each of the related latent variables, and (b) model fit comparisons between a single-factor vs. a two-factor model.

First, we computed the bivariate latent covariance among latent variables (with their error variance constrained to be 1 , so this is interpreted as correlations), as reported in Panel A of Table A2 in the online appendix. The results show that, consistent with prior research on this topic (e.g., Gil de Zúñiga et al., 2017), social media news use was positively correlated with all of the subdimensions of NFM perception. Though, at the same time, the result also suggested that there are some noticeable differences in their magnitudes of zeroorder correlations across three sub-dimensions. Social media news use was most strongly correlated with the "not seeking" dimension $(\Phi=.769)$, but to a lesser extent with the "reliance on peers" dimension $(\Phi=.361)$, and least strongly with the "being informed" dimension $(\Phi=.124$, all $p<.05)$. This is a particularly noteworthy pattern, given that bivariate correlations of the three NFM subdimensions are very much similar to each other (all $\Phi$ s about .5 to .6 range). Also, the "being informed" dimension was negatively correlated with cynicism $(\Phi=-.258, p<.001)$, which was indeed expected based on the theoretical meanings of the two constructs. As such, results showed initial evidence of convergent validity of our multidimensional conceptualization of NFM perception, although we would be cautious, as this result does not correct for selfselection bias in cross-sectional data. 
Next, the covariance between latent variables (again with error variances set to zero) was constrained to 1 to yield a constrained model (this is equivalent to specifying the single-factor model, treating each of the sub-dimensions of NFM to be equal to each of the related latent variables). Subsequently, differences in fit statistics between the single-factor and two-factor models (i.e., the model that freely estimates covariance without equality constraints) were computed, with 1 $d f$ for $\chi 2$-difference tests, as reported in Panel B of Table A2 in the online appendix. A substantial improvement in fit between the single-factor and twofactor model suggested that, although they are meaningfully correlated, the latent variables are unique to each other, thereby tapping different constructs. Coupled with earlier results showing that each of NFM subdimensions is correlated with the other variables differently, this provides evidence of discriminant validity.

\section{Effects of Social Media Use on Cynicism Through NFM: Propensity Score Weighting}

Having established initial evidence of convergent and divergent validity, we now move to the correlates and its possible consequences of NFM perception. Since we are interested in effects of social media news use on three NFM subdimensions, and in turn effects of those sub-dimensions on political cynicism, we estimated two CBGPS models predicting continuous "treatment" variable, social media news use and NFM perception respectively, as a function of the host of pre-treatment covariates outlined above. Figure 1 below reports the covariate balance (i.e., absolute values of Pearson correlations between a "treatment" variable and a set of covariates) before (each upper panel) and after (each lower panel) weighting. As can be seen in Figure 1, the estimated CBGPS weights substantially reduced the degree of imbalance in the data, such that the maximum covariate imbalance in post-weighted data does not exceed 0.1 (which is an adequate level of covariate balance in continuous treatment cases: Zhu, Coffman, \& Ghosh, 2015). Resulting CBGPS weights were then further utilized in outcome analysis estimating NFM perception (mediator) and political cynicism (the dependent variable), and later in the Monte-Carlo simulation method for estimating mediation effects. Detailed information regarding the propensity score weighting procedures are reported in Table A3 of the online appendix (we also present side-by-side results of identical models without propensity score weighting in Table A4 of the online appendix). Table 2 below reports the results adjusted for propensity score weighting, which produces more accurate (and often more conservative) estimates compared to typical OLS estimates.

Our first set of hypotheses (H1a and H1b) predicted that social media use for news would be positively associated with "being informed" and "not seeking" 
Panel A: Covariate balance, Social media news use

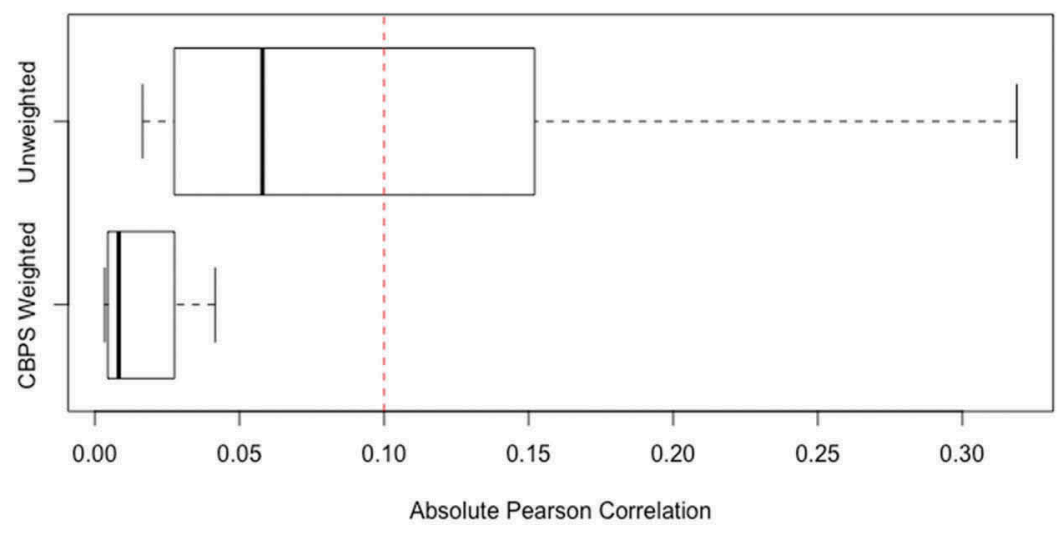

Panel B: Covariate balance, NFM perception

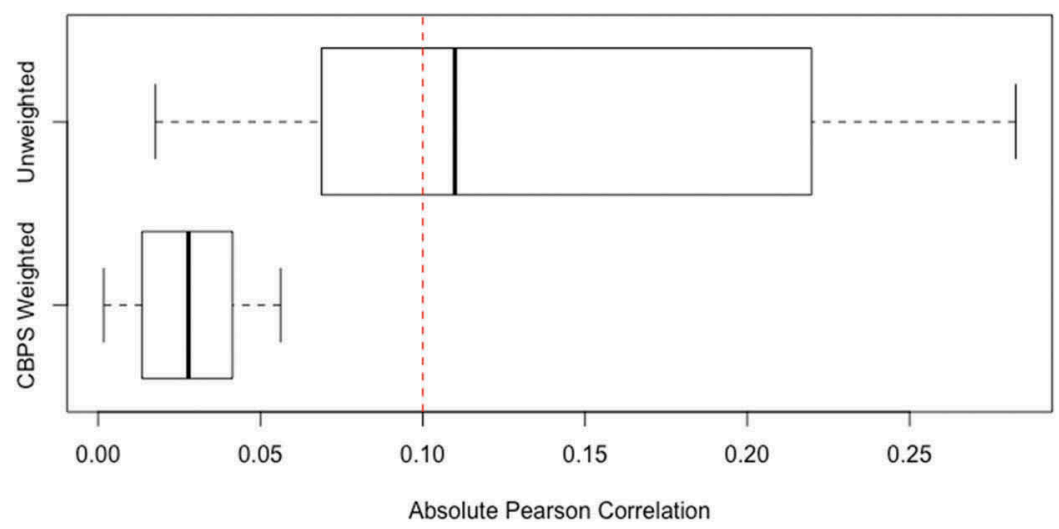

FIGURE 1 Covariate balance plots. The "treatment" variable in upper panel is social media news use, and the "treatment" variable in lower panel is NFM perception. The figures show that covariate balance (in terms of absolute Person correlation between treatment variable and the pre-treatment covariates) is substantially improved by CBPS weighting, such that none of the pre-treatment covariates are correlated higher than 0.1 with the treatment variable after weighting. A detailed information about each covariate balance statistics is reported in Table A3 of the online appendix.

sub-dimensions of the NFM perception. These expectations received strong support by our data, in that social media news use significantly and positively predicted the informed (H1a: $b=.175, S E=.053$ ), not seeking (H1b: $b=.541$, $S E=.047)$, and the reliance on peers dimension as well $(\mathrm{H} 2 \mathrm{~b}: b=.324$, 
TABLE 2

Predictors of NFM Perception and Political Cynicism, Using Post-CBGPS Weighting (Standard Errors in Parentheses)

\begin{tabular}{|c|c|c|c|c|}
\hline & NFM reliance & NFM informed & NFM not seeking & DV cynicism \\
\hline (Intercept) & $3.255(.738)^{* * *}$ & $4.908(.788)^{* * *}$ & $2.785(.711)^{* * *}$ & $\mathbf{3 . 4 6 5}(.210)^{* * *}$ \\
\hline \multicolumn{5}{|l|}{ Focal predictors } \\
\hline Social media news use & $.324(.049)^{* * *}$ & $.175(.053)^{* * *}$ & $.541(.047)^{* * *}$ & $-.035(.014)^{*}$ \\
\hline Alter expertise & $.478(.164)^{* *}$ & $.473(.175)^{* *}$ & $.088(.158)$ & $-.135(.042)^{* *}$ \\
\hline \multicolumn{5}{|l|}{ Mediators } \\
\hline NFM - Reliance & & & & $.033(.013)^{* *}$ \\
\hline NFM - Informed & & & & $-.038(.012)^{* *}$ \\
\hline NFM - Not seeking & & & & $.011(.012)$ \\
\hline \multicolumn{5}{|l|}{ Controls } \\
\hline Interest & $-.429(.145)^{* *}$ & $-.592(.154)^{* * *}$ & $-.345(.139)^{*}$ & $.108(.038)^{* *}$ \\
\hline Discussion freq & $-.092(.144)$ & $-.100(.154)$ & $.104(.139)$ & $-.030(.038)$ \\
\hline Internal efficacy & $-.085(.081)$ & $.085(.087)$ & $-.013(.078)$ & $-.195(.022)^{* * *}$ \\
\hline \multicolumn{5}{|l|}{ Demographics } \\
\hline Gender $($ Female $=1)$ & $.135(.193)$ & $.144(.206)$ & $.178(.186)$ & $.060(.051)$ \\
\hline Education & $-.086(.036)^{*}$ & $-.139(.039)^{* * *}$ & $-.151(.035)^{* * *}$ & $.004(.009)$ \\
\hline Age (in 10 years) & $-.020(.062)$ & $.073(.066)$ & $.284(.059)^{* * *}$ & $-.042(.018)^{*}$ \\
\hline $\mathrm{R}^{2}\left(\right.$ Adjusted $\mathrm{R}^{2}$ ) & $.125(.112)$ & $.117(.103)$ & $.276(.265)$ & $.213(.197)$ \\
\hline Number of observations & 532 & 532 & 532 & 532 \\
\hline RMSE & 0.094 & 0.100 & 0.090 & 0.025 \\
\hline
\end{tabular}

Note. Significant unstandardized coefficients are bolded. ${ }^{* *} p<.001,{ }^{* *} p<.01,{ }^{*} p<.05$.

$S E=.049$, all $p<.001$ ), even after controlling for a set of covariates (such as political interest, internal efficacy, and demographics) and possible selfselection bias (via propensity score weighting). Additionally, H2a predicted that alter political expertise would be significantly related to the reliance on peers dimension, which is strongly supported by our data (H2a: $b=.478$, $S E=.164, p<.01)$.

Besides those hypothesize effects, a few results deserve further mention. First, we found that education and political interest all strongly and negatively predict all three NFM sub-dimensions. Given the passive nature of the NFM perception, these results indeed make sense, in that more educated and interested citizens tend to actively consume political information (Ksiazek et al., 2010; Prior, 2005). Furthermore, we observe that, in addition to the hypothesized reliance on peers dimension, alter political expertise is also positively related to the being informed $(b=.473, S E=.175, p<.01)$ but not to the not seeking dimension $(b=.088, S E=.158, p>.05)$. When surrounded with knowledgeable peers, one may also come to believe that they themselves are also sufficiently informed as a result of relying on such contacts in acquiring political information; but it seems that merely being 
surrounded by such contacts does not lower one's motivation for active information seeking.

Turning to the impact of each NFM sub-dimension on political cynicism, the results show that while the being informed dimension (H3c: $b=-.038$, $S E=.012, p<.01)$ is negatively associated with political cynicism, the reliance on peers dimension (H3a: $b=.033, S E=.013, p<.01$ ) is positively associated with political cynicism. The not seeking dimension did not reach the conventional level of statistical significance as predicted by H3b.

To better understand the consequences of different dimensions of NFM perception on political cynicism (and the value of such a multidimensional conceptualization over a monotonic conceptualization), we conducted Monte Carlo (MC) method-based mediation inferences as described in Hayes (2017) and in Preacher and Selig (2012). The MC method is a particularly appropriate choice here since it can easily accommodate complex mediation models that may take a long time to converge or may randomly generate a constant variance of test statistics when directly bootstrapped (such as multilevel models or regression models with propensity score weights as here). We take parameter estimates and their asymptotic variances and covariance from regression models reported in Table 2, and then generated the joint distribution of indirect effects from 20,000 replicated draws to construct $95 \%$ confidence intervals for indirect effects. The results are reported in Table 3 below.

When we look at the simple mediation model with a single composite scale of NFM as a mediator, we find that NFM perception as a whole is not significantly associated with cynicism (indirect effect $=-.0003,95 \%$ MC CIs $=[-.0101, .0093]$ ). Yet when we consider potentially differential pathways by utilizing three subdimensions separately, we find that the "reliance on peers" dimension (indirect

TABLE 3

Estimated Indirect Effects of Social Media News Use on Cynicism through NFM Perception Dimensions and Their 95\% Distributions from Monte Carlo Methods

\begin{tabular}{lcc}
\hline & \multicolumn{2}{c}{$D V$ : Political Cynicism } \\
\cline { 2 - 3 } IV: Social media news use & NFM Composite & NFM Sub-scales \\
\hline Direct effect & $-.0251(.0135)$ & $-.0352(.0142)$ \\
Indirect effect & & \\
NFM: Composite & $-.0003[-.0101, .0093]$ & $\mathbf{. 0 0 5 7}[.0025, .0200]$ \\
$\quad$ Reliance & & $-\mathbf{. 0 0 6 5}[-.0133,-.0016]$ \\
$\quad$ Being informed & & $.0018[-.0071, .0191]$ \\
\hline Not Seeking & &
\end{tabular}

Note. Unstandardized coefficients in bold are significant at $p<.05$ level, or $95 \%$ confidence intervals does not include zero. Standard errors in parentheses (for direct effects), and 95\% Confidence Intervals from Monte Carlo simulation methods in brackets (for indirect effects). 
effect $=.0057,95 \%$ MC CIs $=[.0025, .0200])$ and "being informed" dimension (indirect effect $=-.0065,95 \% \mathrm{MC} \mathrm{CIs}=[-.0133,-.0016])$ significantly mediate the influence of social media use on cynicism - and more importantly, in the opposite direction to each other. While this confirms H4a and H4c, we do not find compelling evidence that the "not seeking" dimension significantly mediates the influence of social media use (H4b). Nevertheless, the overall pattern suggests that different sub-dimensions of the NFM work against each other in predicting political cynicism, and thus, that the use of a single composite measure of NFM perception may actually mask an important yet much nuanced relationship between social media use and political cynicism.

\section{DISCUSSION AND CONCLUSION}

Following previous contributions on this topic, our study examined what is called the "News Finds Me" perception (Gil de Zúñiga et al., 2017). We specifically focused on its scale refinement in terms of conceptual clarifications by proposing - and empirically establishing - that the NFM should be considered as a tripartite, higher-order construct consisting of "being informed" (epistemic), "not seeking" (motivational), and "reliance on peers" (instrumental) sub-dimensions. We then systematically examined its correlates such as social media use for news and one's social network characteristics, and further uncovered different effects of three sub-dimensions of the NFM perception on citizens' system-level beliefs focusing on political cynicism.

Representing a detachment from more active surveillance needs, the notion of NFM suggests that incidental exposure to news, mainly through day-to-day social media use and through interpersonal interactions with their peers, creates the perception that they are already sufficiently informed about important political problems despite not actively seeking such information (e.g., Toff \& Nielsen, 2018). Largely focusing on the U.S population, previous studies found that social media news use positively contributes to the development of the NFM perception (e.g., Gil de Zúñiga \& Diehl, 2019; Gil de Zúñiga et al., 2017). Our study not only directly corroborate such previous findings in a different geographical context with a considerably different media landscape and internet news use in general (the U.S vs. Austria), but also found that social media news use was significantly correlated with all of the hypothesized sub-dimensions of NFM perception. Besides, our study shows that one's network characteristics also importantly shape NFM perception; individuals are likely to hold a higher NFM perception when they also perceive themselves surrounded with their social network peers who are politically knowledgeable and interested. Consistent with the theoretical perspective that such a "passive" mode of news use may further promote negative 
political consequences, we also found that social media news use may increase political cynicism through the "reliance on peer" dimension. Through careful inspection of the dimensionality of NFM perception, our study therefore contributes to a more nuanced understanding of the relationship between social media news use, one's social network characteristics, and their implications on democratic perceptions through NFM perception.

Despite the fact that inadvertent exposure to political information on social media makes citizens feel confident in keeping up with current affairs, previous studies on this topic suggested that relying on such a passive, incidental mode of news consumption without active involvement does not compensate for the lack of active use of traditional media - those who incidentally encounter news contents without active engagements are actually less likely to be knowledgeable about politics, and for that matter, less likely to actively participate in political processes (e.g., Gil de Zúñiga \& Diehl, 2019; Gil de Zúñiga et al., 2017). This may suggest the possibility that those who score higher on NFM would have higher levels of cynicism as well. However, we instead found that perceptions of being informed - one of the sub-dimensions of NFM - actually decrease citizen's political cynicism. As its positive effect on cynicism suggests, "passive" news consumers may not necessarily become more detached from politics, but may play an active role in democracy despite their illusion of being informed. These contradicting patterns further suggest the multidimensional nature of "News Finds Me Perception" and its complex implications for democratic engagement.

Furthermore, the pattern suggests that the "reliance on peers" dimension increases cynicism, which highlights a much broader implication of the NFM perception. While this dimension captures the passive nature of information "encounter" strategies, it additionally represents "delegation" of deciding what is important and meaningful for individuals. Traditionally, such peer delegation or a general reliance on indirect information seeking via opinion leaders or peers from one's social network - has been regarded as an efficient and costless shortcut for information acquisition, enabling those who are not that interested in politics to behave as if they are fully informed (e.g., Downs, 1957; Sokhey \& McClurg, 2012). Our analysis suggests that instead of enabling those who are less interested in politics to meaningfully participate in politics, such delegation might actually result in a further detachment from the political process - not only in terms of political knowledge acquisition (as evidenced in Gil de Zúñiga \& Diehl, 2019; Gil de Zúñiga et al., 2017) but also in terms of increasing political cynicism, as documented in this study.

This empirical pattern in particular seems to suggest possible negative consequences of the NFM perception may not necessarily be driven by the "not seeking" dimension, but is rather based on the "reliance on peers" dimension. 
Based on our own results here and on some recent qualitative evidence on this topic (e.g., Toff \& Nielsen, 2018), we suppose that the "not seeking" dimension is rather a consequence of both the "reliance on peers" and "informed" dimensions - because I feel confident that I am sufficiently informed by such information delegation, I think I need not further look at what is needed. This observation further suggests that the specific consequences of NFM perception may pan out very differently based on the internal dynamics of NFM subdimensions (e.g., when people perceive that they are not sufficiently informed despite the fact that their friends in social networks provide all necessary information). In other words, we suspect that a specific pattern of interaction between those two sub-dimensions is likely to be key in understanding the particular consequences of NFM perception.

The present findings also suggest the possibility of "channel" differences (e.g., through online communities vs. through the use of news aggregators and websites of news organizations) in the Internet's effect on political cynicism. As suggested by Ceron (2015), while the exposure to news through online communities - mainly through "encountering" news shared by one's peers, much like the use of social media - may represent a "passive" mode of consuming news, using a portal or the websites of news organizations may still involve an active mode of news use. Our results partly collaborate this perspective, such that passive forms of news use (i.e., "reliance on peers") in particular, indeed has a negative consequence for cynicism. Further, this suggests that other forms of using social media may indeed have distinct consequences through NFM perception. For instance, consuming "ambience news" within the current context of second screening - using multiple devices and screens to interact with information at the same time such as news on TV, on smartphones, and/or laptops (Gil de Zúñiga \& Liu, 2017, Barnidge, Diehl, \& Rojas, 2019; Chadwick, O’Loughlin, \& Vaccari, 2017) - may lead to similar consequences. In such a context, people may feel they are well informed, and can rely on peers to be informed, although they may feel they still need to actively seek news to further verify facts, discuss public affairs issues, or simply to learn more about political issues. This theoretical suggestion, of course, remains empirically untested; future research is therefore advised to further explore this possibility.

Methodologically, our analysis also uncovers more nuanced patterns of association between sub-dimensions of NFM and their consequences. We demonstrate that separately considering the three NFM sub-dimensions contributes to a much better understanding of the impact of social media. While relying on a single composite scale may reasonably work well if a researcher is interested in its monotonic relationship with other variables (such as political knowledge: Gil de Zúñiga et al., 2017), doing so may mask important yet nuanced dynamics among those different sub-dimensions, especially when there are theoretical reasons to suspect such differential associations. 
We acknowledge that a single-country, cross-sectional data with a rather small sample size does not permit us to make very strong tests of our hypotheses, and is particularly unable to completely resolve the issue of endogeneity, although our use of propensity score weighting may reasonably alleviate such concerns. While prior evidence on this topic suggests the specific chain of causality from social media use to NFM perception on the one hand, and from the NFM perception to its consequences (e.g., Gil de Zúñiga et al., 2017; Valenzuela et al., 2018, May), establishing a robust causal evidence is a tricky endeavor, especially when our measurement of the key concept relies on participants' retrospective self-reports. Future work on this topic is therefore advised to rely on cross-national, longitudinal data with better measurement techniques to robustly explore the antecedents and consequences of NFM perceptions, and its implications for democracy.

The limited number of measurement items per sub-dimension (i.e., two per sub-dimension) also provided us a less-than-ideal setup for rigorously testing our expectations. Given the complicated nature of the NFM construct, future studies are advised to employ qualitative, in-depth interviews (e.g., Toff \& Nielsen, 2018) or cross-national comparisons (e.g., Fletcher \& Nielsen, 2018) in the development of more comprehensive sets of measurement items and advancing possible additional sub-dimensions. In addition, exploring possible consequences of NFM on different system-level beliefs, such as trust towards various political institutions, would be a fruitful endeavor for future studies.

Lastly, in establishing convergent and divergent validity, we have relied on a somewhat limited set of variables (that were also used later on the main analysis) rather than utilizing more directly related yet auxiliary constructs such as avoidance of news, incidental news motivation, or in general attention and elaboration during news exposure. While the nature of our survey setting has practically limited us to a small set of variables available in our dataset, our results nevertheless provide very initial evidence towards establishing the multidimensionality of the NFM construct. Future studies will be benefitted from the use of more theoretically related auxiliary constructs in further clarifying the nature and meanings of the NFM perception and its implications on contemporary news environments.

News media has long been the core mechanism of how citizens acquire and make sense of political information, yet an increasing trend of inadvertent exposure, at the expense of direct and active engagements with conventional forms of news, brings about new opportunities and unforeseen challenges to a healthy democratic citizenry. Given social media's likely rising significance in terms of news provision in the future, it is important to understand cognitive and behavioral implications of such news consumption patterns. 


\section{FUNDING}

The author(s) disclosed receipt of the following financial support for the research, authorship, and/or publication of this article: This work was supported and funded by the Platform for Surveys, Methods and Empirical Analyses (PUMA), financed by the Austrian Federal Ministry of Education, Science and Research. The funders had no role in study design, data collection and analysis, decision to publish, or preparation of the manuscript. Any opinions, findings, and conclusions or recommendations expressed in this material are those of the author(s) and do not necessarily reflect the views of the PUMA and Austrian Federal Ministry of Education, Science and Research.

\section{SUPPLEMENTAL DATA}

Supplemental data for this article can be accessed here.

\section{ORCID}

Hyunjin Song (ㄱ) http://orcid.org/0000-0001-7752-3035

Homero Gil de Zúñiga (1) http://orcid.org/0000-0002-4187-3604

Hajo G. Boomgaarden (1) http://orcid.org/0000-0002-5260-1284

\section{REFERENCES}

Bailard, C. S. (2014). Democracy's double-edged sword: How Internet use changes citizens' views of their government. Baltimore, MD: Johns Hopkins University Press.

Barnidge, M., Diehl, T., \& Rojas, H. (2019). Second screening for news and digital divides. Social Science Computer Review, 37(1), 55-72. doi:10.1177/0894439317750840

Berelson, B. R., Lazarsfeld, P. F., \& McPhee, W. N. (1954). Voting: A study of opinion formation in a presidential campaign. Chicago, IL: University of Chicago Press.

Bode, L. (2016). Political news in the news feed: Learning politics from social media. Mass Communication and Society, 19, 24-48. doi:10.1080/15205436.2015.1045149

Boukes, M., \& Boomgaarden, H. G. (2015). Soft news with hard consequences? Introducing a nuanced measure of soft versus hard news exposure and its relationship with political cynicism. Communication Research, 42, 701-731. doi:10.1177/0093650214537520

Burggraaff, C., \& Trilling, D. (2017). Through a different gate: An automated content analysis of how online news and print news differ. Journalism. Advance online publication. doi:10.1177/ 1464884917716699

Cappella, J. N., \& Jamieson, K. H. (1996). News frames, political cynicism, and media cynicism. The Annals of the American Academy of Political and Social Science, 546, 71-84. doi:10.1177/ 0002716296546001007 
Ceron, A. (2015). Internet, news, and political trust: The difference between social media and online media outlets. Journal of Computer-Mediated Communication, 20, 487-503. doi:10.1111/ jcc4.2015.20.issue-5

Chadwick, A., O'Loughlin, B., \& Vaccari, C. (2017). Why people dual screen political debates and why it matters for democratic engagement. Journal of Broadcasting \& Electronic Media, 61(2), 220-239. doi:10.1080/08838151.2017.1309415

Cook, T. E., \& Gronke, P. (2005). The skeptical American: Revisiting the meanings of trust in government and confidence in institutions. The Journal of Politics, 67, 784-803. doi:10.1111/ j.1468-2508.2005.00339.x

De Vreese, C. H., \& Elenbaas, M. (2008). Media in the game of politics: Effects of strategic metacoverage on political cynicism. The International Journal of Press/Politics, 13, 285-309. doi: $10.1177 / 1940161208319650$

Downs, A. (1957). An economic theory of political action in a democracy. Journal of Political Economy, 65, 135-150. doi:10.1086/257897

Elenbaas, M., Boomgaarden, H. G., Schuck, A. R., \& de Vreese, C. H. (2013). The impact of media coverage and motivation on performance-relevant information. Political Communication, 30, 1-16. doi:10.1080/10584609.2012.737411

Eveland, W. P., Jr, Hutchens, M. J., \& Shen, F. (2009). Exposure, attention, or "use" of news? Assessing aspects of the reliability and validity of a central concept in political communication research. Communication Methods and Measures, 3, 223-244. doi:10.1080/19312450903378925

Fieschi, C., \& Heywood, P. (2004). Trust, cynicism and populist anti-politics. Journal of Political Ideologies, 9, 289-309. doi:10.1080/1356931042000263537

Fletcher, R., \& Nielsen, R. K. (2018). Are people incidentally exposed to news on social media? A comparative analysis. New Media \& Society, 20, 2450-2468. doi:10.1177/1461444817724170

Fong, C., Hazlett, C., \& Imai, K. (2018). Covariate balancing propensity score for a continuous treatment: Application to the efficacy of political advertisements. The Annals of Applied Statistics, 12, 156-177. doi:10.1214/17-AOAS1101

Fong, C., Ratkovic, M., \& Imai, K. (2018). CBPS: Covariate balancing propensity score. $R$ package version 0.19. Retrieved from: https://CRAN.R-project.org/package=CBPS

Gil de Zúñiga, H., \& Diehl, T. (2019). News finds me perception and democracy: Effects on political knowledge, political interest, and voting. New Media \& Society, 21, 1253-1271. doi: $10.1177 / 1461444818817548$

Gil de Zúñiga, H., \& Liu, J. H. (2017). Second screening politics in the social media sphere: Advancing research on dual screen use in political communication with evidence from 20 countries. Journal of Broadcasting \& Electronic Media, 61(2), 193-219. doi:10.1080/ 08838151.2017.1309420

Gil de Zúñiga, H., Weeks, B., \& Ardèvol-Abreu, A. (2017). Effects of the news-finds-me perception in communication: Social media use implications for news seeking and learning about politics. Journal of Computer-Mediated Communication, 22, 105-123. doi:10.1111/jcc4.2017.22.issue-3

Hayes, A. F. (2017). Introduction to mediation, moderation, and conditional process analysis: A regression-based approach (2nd ed.). New York, NY: The Guilford Press.

Hayes, A. F., Glynn, C. J., \& Shanahan, J. (2005). Willingness to self-censor: A construct and measurement tool for public opinion research. International Journal of Public Opinion Research, 17, 298-323. doi:10.1093/ijpor/edh073

Huckfeldt, R. (2001). The social communication of political expertise. American Journal of Political Science, 45, 425-438. doi:10.2307/2669350

Hutchens, M. J., Hmielowski, J. D., Pinkleton, B. E., \& Beam, M. A. (2016). A spiral of skepticism? The relationship between citizens' involvement with campaign information to their skepticism and political knowledge. Journalism \& Mass Communication Quarterly, 93, 1073-1090. doi:10.1177/1077699016654439 
Imai, K., \& Ratkovic, M. (2014). Covariate balancing propensity score. Journal of the Royal Statistical Society: Series B (statistical Methodology), 76, 243-263. doi:10.1111/rssb.12027

Kim, Y., Chen, H. T., \& de Zúñiga, H. G. (2013). Stumbling upon news on the Internet: Effects of incidental news exposure and relative entertainment use on political engagement. Computers in Human Behavior, 29, 2607-2614. doi:10.1016/j.chb.2013.06.005

Kriesi, H., Grande, E., Dolezal, M., Helbling, M., Höglinger, D., Hutter, S., \& Wüest, B. (2012). Political conflict in western Europe. Cambridge, UK: Cambridge University Press.

Ksiazek, T. B., Malthouse, E. C., \& Webster, J. G. (2010). News-seekers and avoiders: Exploring patterns of total news consumption across media and the relationship to civic participation. Journal of Broadcasting \& Electronic Media, 54, 551-568. doi:10.1080/08838151.2010.519808

Lee, C. S., \& Ma, L. (2012). News sharing in social media: The effect of gratifications and prior experience. Computers in Human Behavior, 28, 331-339. doi:10.1016/j.chb.2011.10.002

Lee, J., \& Song, H. (2017). Why people post news on social networking sites: A focus on technology adoption, media bias, and partisanship strength. Electronic News, 11, 59-79. doi: $10.1177 / 1931243117692084$

Messing, S., \& Westwood, S. J. (2014). Selective exposure in the age of social media: Endorsements trump partisan source affiliation when selecting news online. Communication Research, 41, 1042-1063. doi:10.1177/0093650212466406

Newman, N., Fletcher, R., Kalogeropoulos, A., Levy, D. A. L., \& Nielsen, R. K. (2018). Reuters Institute Digital News Report 2018. Retrieved from: https://reutersinstitute.politics.ox.ac.uk/sites/ default/files/digital-news-report-2018.pdf

Pinkleton, B. E., \& Austin, E. W. (2002). Exploring relationships among media use frequency, perceived media importance, and media satisfaction in political disaffection and efficacy. Mass Communication \& Society, 5, 141-163. doi:10.1207/S15327825MCS0502_3

Preacher, K. J., \& Selig, J. P. (2012). Advantages of Monte Carlo confidence intervals for indirect effects. Communication Methods and Measures, 6, 77-98. doi:10.1080/19312458.2012.679848

Prior, M. (2005). News vs. entertainment: How increasing media choice widens gaps in political knowledge and turnout. American Journal of Political Science, 49, 577-592. doi:10.1111/ ajps.2005.49.issue-3

Rosseel, Y. (2012). Lavaan: An R package for structural equation modeling and more. Version 0.5-12 (BETA). Journal of Statistical Software, 48, 1-36. doi:10.18637/jss.v048.i02

Schuck, A. R., Boomgaarden, H. G., \& de Vreese, C. H. (2013). Cynics all around? The impact of election news on political cynicism in comparative perspective. Journal of Communication, 63, 287-311. doi:10.1111/jcom.12023

Shehata, A. (2014). Game frames, issue frames, and mobilization: Disentangling the effects of frame exposure and motivated news attention on political cynicism and engagement. International Journal of Public Opinion Research, 26, 157-177. doi:10.1093/ijpor/edt034

Sokhey, A. E., \& McClurg, S. D. (2012). Social networks and correct voting. The Journal of Politics, 74, 751-764. doi:10.1017/S0022381612000461

Toff, B., \& Nielsen, R. K. (2018). "I just Google it": Folk theories of distributed discovery. Journal of Communication, 68, 636-657. doi:10.1093/joc/jqy009

Trilling, D., Tolochko, P., \& Burscher, B. (2017). From newsworthiness to shareworthiness: How to predict news sharing based on article characteristics. Journalism \& Mass Communication Quarterly, 94, 38-60. doi:10.1177/1077699016654682

Turcotte, J., York, C., Irving, J., Scholl, R. M., \& Pingree, R. J. (2015). News recommendations from social media opinion leaders: Effects on media trust and information seeking. Journal of Computer-Mediated Communication, 20, 520-535. doi:10.1111/jcc4.2015.20.issue-5

Valentino, N. A., Hutchings, V. L., Banks, A. J., \& Davis, A. K. (2008). Is a worried citizen a good citizen? Emotions, political information seeking, and learning via the internet. Political Psychology, 29, 247-273. doi:10.1111/pops.2008.29.issue-2 
Valenzuela, S., Bachmann, I., \& Gil de Zúñiga, H. (2018). Positive, negative or null effects? A panel study on political learning from social media. Prague, Czech Republic: International Communication Association.

Valeriani, A., \& Vaccari, C. (2016). Accidental exposure to politics on social media as online participation equalizer in Germany, Italy, and the United Kingdom. New Media \& Society, 18, 1857-1874. doi:10.1177/1461444815616223

Weeks, B. E., Lane, D. S., Kim, D. H., Lee, S. S., \& Kwak, N. (2017). Incidental exposure, selective exposure, and political information sharing: Integrating online exposure patterns and expression on social media. Journal of Computer-Mediated Communication, 22, 363-379. doi:10.1111/ jcc4.2017.22.issue-6

Zhu, Y., Coffman, D. L., \& Ghosh, D. (2015). A boosting algorithm for estimating generalized propensity scores with continuous treatments. Journal of Causal Inference, 3, 25-40. doi:10.1515/ jci-2014-0022 